\title{
2. RESEÑA DE SENTENCIAS
}

SUMARIO: I. ACTO ADMINISTRATIVO: 1. EJECUCIÓN FORZOSA. 2. Nulidad DEClarada POR La ADMINISTRACión 3. TeORía dE laS NULIDADES.-II. BIENES: 1. CAMINO PÚBLICO: NO ES PRECISO ACTO EXPRESO DE AFECTACIÓN. 2. CAMINO PÚBLICO: NO PRECISA INSCRIPCIÓN EN EL Registro de LA PROPIEDAD. 3. ReCUPERACIÓN ADMINISTRATIVA.-III. CONTRATACION ADMINISTRATIVA: 1. CONCURSo: EXIGENCIA DEL PRoyecto técnico. 2. Contrato NUlo y obra EJECUTADA. 3. REVISIÓN DE PRECIOS EN LA ADMINISTRACIÓN LOCAL. IV. EXPROPIACION FORZOSA: 1. JURADO: CONSTITUCIÓN. 2. PREMIO DE AFECCIÓN: BASE DE APLICACIÓN.-V. FUNCIONARIOS: ADMINISTRACIÓN LOCAL: INTERINOS, EVENTUALES, TEMPOREROS: PAGO DE CUOTAS A LA M.U.N.P.A.L.-VI. JURISDICCION CONTENCIOSO-ADMINISTRATIVA: 1. EJERCICIO DE ACCIONES POR LAS CORPORACIONES LOCALES. 2. NOTIFICACIÓN DEFECTUOSA.-VII. POLICIA MUNICIPAL: 1. ACTIVIDADES MOLESTAS, INSALUBRES, NOCIVAS Y PELIGROSAS: MATADERO MUNICIPAL. 2. CANTERAS: LICENCIA MUNICIPAL AL EFECTO. 3. LICENCIAS: CARÁCTER REGLADO. 4. RESOLUción de la Comisión PRovincial de URBanismo QUE EXIGE QUE EL AYUNTAMIENTO DECLARE ERRÓNEA UNA LICENCIA OTORGADA. 5. LICENCIA DE APERTURA DE ESTABLECIMIENTO: MEDIDAS CORRECTORAS POSTERIORES. 6. LICENCIA DE OBRAS: CONCEPTO. 7. LICENCIA DE OBRAS: CONDICIONES IMPUESTAS SIN BASE LEGAL. 8. LICENCIAS: PAGO DE TASA: NO SUPONE NECESARIAMENTE EL OTORGAMIENTO DE LA LICENCIA. 9. LICENCIA DE OBRAS: PRINCIPIOS DE IGUALDAD ANTE LA LEY Y DE LEGALIDAD. 10. LICENCIA DE OBRAS: SUSPENSIÓN.-VIII. RUINA: 1. Declaración. 2. Edificio fuera de alineación. 3. Procedencia DE SU DECLARACIÓN. 4. OBRaS ORDENADAS POR EL AYUNTAMIENTO: NO ES PRECISA LA LICENCIA.-IX. PROCEDIMIENTO ADMINISTRATIVO: CÓMPUTO DE PLAZO.-X. RESPONSABILIDAD DE LA ADMINISTRACION: RESPONSABILIDAD PATRIMONIAL OBJETIVA.XI. SOLARES E INMUEBLES DE EDIFICACION FORZOSA: 
DeSa hucio: INDEMNIZACIÓN.-XII. URBANISMO: 1. FiJación DE ZONAS Y DESTINO URBANÍSTICO. 2. ORDENANZAS MUNICIPALES CONtrarias al Plan. 3. Plan general y planes parciales. 4. Plan PARCIAL: FALTA. 5. PlanES: IMPORTANCIA DEL ESTUdIO ECONÓMICO. 6. TERRENO DESTINAdo a Vía PÚblica. 7. Zonas VERDES: PROTECCIÓN ESPECIAL QUE ESTABLECE LA LEY DE 2 DE DICIEMBRE DE 1963.XIII. ZONA MARITIMO-TERRESTRE: EXIGENCIA DE LA LICENCIA MUNICIPAL.

\section{ACTO ADMINISTRATIVO}

\section{EJECUCIÓN FORZOSA}

ConsIDERANDO: Que establecida por el artículo 170 de la Ley del Suelo de 12 de mayo de 1956-según precepto subsistente en la Ley de Reforma de 2 de mayo de 1975, que ha pasado a integrar, con idéntica redacción, el artículo 183 del Texto Refundido aprobado por Real Decreto de 9 de abril det actual año-, que «cuando alguna construcción o parte de ella estuviera en estado ruinoso, el Ayuntamiento, de oficio o a instancia de cualquier interesado, declarará y acordará la total o parcial demolición, previa audiencia del propietario y de los moradores, salvo inminente peligro que lo impidiera", determina en el número 3 del propio artículo que "si el propietario no cumpliera lo acordado por el Ayuntamiento, lo ejecutará éste a costa del obligado". Tal disposición representa una manifestación de la facultad concedida a la Administración Pública por el artículo 102 de la Ley de Procedimiento Administrativo para proceder, a través de sus Organos competentes, previo apercibimiento, «a la ejecución forzosa de los actos adminis. trativos", que, según el artículo 104, b), puede efectuarse por medio de la "ejecución subsidiaria", a que, por lo dispuesto en el artículo 106, habrá lugar «cuando se trate de actos que por no ser personalísimos puedan ser realizados por sujeto distinto del obligado», en cuyo caso "la Administración realizará el acto por sí o a través de las personas que determine, a costa del obligado». (Sentencia de 18 de octubre de 1980, Ar. 3.916.)

\section{NULIDAD DECLARADA POR LA ADMINISTRACIÓN}

CONSIDERANDO: Que la jurisprudencia se ha venido encargando de controlar y cerrar el paso a posibles abusos de la Administración en el ejercicio de este tipo de actos revocatorios, declarando que en Derecho administrativo, por no tener aplicación el artículo 4 del Código Civil (texto del antiguo Libro Preliminar), la nulidad de actuaciones constituye una excepción, por lo que esta nulidad sólo se da en los casos taxativamente marca. dos en el artículo 47 de la Ley de Procedimiento Administrativo-sentencia de 23 de octubre de 1964-, habiéndose dicho en otra ocasión que la auto- 
rización concedida no podía revocarse de plano, como se hizo, porque el caso no se encontraba en ninguno de los supuestos del artículo 109, en relación con el artículo 47 de la Ley de Procedimiento Administrativo, ni por parte de la Administración se había dado cumplimiento a lo preceptuado en el artículo 110 de ia expresada Ley-sentencia de 28 de junio de 1964-; porque no todos los defectos procedimentales tienen los mismos efectos, ni producen las mismas consecuencias-sentencia de 17 de febrero de 1960-, por lo que únicamente deben tomarse en consideración agravisimas infracciones legales»-sentencia de 22 de febrero de 1963-, equivalentes a la llamada "via de hecho", consistente en que la omisión del cauce procedimental sea "completa y categórica», lo que impide decretar la nulidad cuando la omisión sólo es parcial-sentencia de 27 de diciembre de 1962-, al no poder soslayarse la esencial significación que en la redacción de la norma tienen las palabras «total y absolutamente»-sentencia de 7 de marzo de 1963-. (Sentencia de 4 de julio de 1980, Ar. 3.412.)

\section{TeORÍA DE LAS NULIDADES}

CONSIDERANDO: Que una reiterada jurisprudencia viene proclamando la necesidad de administrar con prudencia y moderación la teoria de las nulidades, en el sentido de valorar adecuadamente todos los aspectos positivos y negativos de su aplicación, destacándose en este sentido, que la salvaguardia de las formalidades es garantía, tanto de la Administración como de los administrados, constituyendo un elemento decisivo para ello, al asegurar una actuación vinculada siempre a los trámites y al procedimiento preestablecido, de lo que se infiere, que para una recta aplicación de la nulidad establecida en el apartado c) del artículo 47, antes aludido, el empleo de los dos adverbios alli reflejados-total y absolutamente-recalcan la necesidad de que se haya prescindido por entero de un modo manifiesto $y$ terminante del procedimiento obligado para elaborar el correspondiente acto administrativo, es decir, para que se dé esta nulidad de pleno derecho es imprescindible no la infracción de alguno o algumos de los trámites, sino la falta total de procedimiento para dictar el acto. (Sentencia de 21 de octubre de 1980, Ar. 3.925.)

\section{BIENES}

\section{CAMINo PÚblico: No ES PRECISO aCto EXPRESO DE AFECTACIÓN}

Las pruebas aportadas acreditan de una manera indiscutible la realidad $y$ vigencia del camino vecinal, rural o carretero, denominado "camino de Galapagar a Colmenarejo (de la Dehesa Vieja)", por no existir constancia en contra de la afectación o uso real de la via rural al uso público del camino, tanto si examinamos la cuestión en base de las características intrínsecas como extrínsecas atribuibles al bien, al no resultar, en esta materia, preci- 
sos inexcusablemente actos formales de adscripción o desafectación, $y$ sî manifestarse, como hecho notorio, el real de la afectación al uso público - sentencias de 12 de junio de 1959, 9 de abril de 1963, 7 de diciembre de 1973, etc.-municipal (Sentencia de 23 de septiembre de 1980, Ar. 3.447.)

\section{Camino PÚblico: NO PRECISA INSCRIPCIÓN EN EL REgISTRO DE LA PROPIEDAD}

Es inoperante el argumento jurídico que esgrimía el propietario de la finca como soporte de su acción de cierre del camino, que al ser una vía pública municipal de uso público no necesitaba constar en el Registro de la Propiedad para ser eficaz, frente a todos, tal como se desprende de su naturaleza juridico-pública (extra-comercio) consagrada en el articulo 188 y concordantes de la Ley de Régimen Local, en armonía con lo también dispuesto en el artículo $5 .^{\circ}$ del Reglamento Hipotecario, sin que la norma contenida en la disposición transitoria $1 .^{\circ}$ de la Ley Hipotecaria pueda suponer apoyo bastante para declarar extinguida una servidumbre de camino público, dado que dicha norma responde al deseo del legislador de hacer desaparecer del Registro las menciones como sistema de hacer constar en ét los actos por ellas amparados-para acomodarse al nuevo régimen instaurado-con objeto de conseguir un régimen general uniforme (párrafo 2. apartado a), disposición transitoria 1." de la propia Ley) y cuyo encaje en cuanto a su valoración de virtualidad o eficacia vendría trasladado al juicio de dominio, ajeno a este ámbito, puesto que aquí probado el hecho real o físico del camino vecinal, abierto al público (afectación manifestada como hecho notorio) su libre tránsito es una exigencia institucional que et Ayuntamiento (como titular del bien) tiene obligación legal de imponer (artículos 370, 373, 188 y concordantes de la Ley de Régimen Local y 338 del Reglamento de Organización, Funcionamiento y Régimen Jurídico, y 55 y siguientes del Reglamento de Bienes). (Sentencia de 23 de septiembre de 1980, Ar. 3.447.)

\section{RECUPERACIÓN ADMINISTRATIVA}

Constderando: Que partiendo de las anteriores premisas, esto es, de la naturaleza privilegiada y del carácter estrictamente posesorio de esta autotutela, la misma jurisprudencia ha venido exigiendo, para el exito de esta acción interdictal administrativa, la existencia de una prueba completa y patente de estos hechos: $1^{\circ}$, sometimiento de los bienes a un dominio o a un uso público; 2., perturbación por aquel contra quien se dirige la acción municipal-sentencias de 20 de marzo de 1969, 13 de mayo de 1976 y 20 de mayo, 23 de octubre y 5 de noviembre de 1974 .

CONSIDERANDO: Que no obstante lo dicho, la propia jurisprudencia no ha tenido más remedio que flexibilizar lo que pudiera haber de dogmatismo en su postura, afirmando que no cabe minimizar la acción administrativa, hasta el extremo de hacerla irrealizable, cual ocurriría si se hallara mania- 
tada ante toda precedente intervención, lo que indudablemente debe valorarse con mayor intensidad cuando de bienes de uso público se trate, ya que éstos tienen de por sí su propio justificante «de facto», que los delata como tales, aunque no figuren en ningún inventario municipal-sentencia de 29 de marzo de 1969-. (Sentencia de 20 de octubre de 1980, Ar. 3.920.)

\section{CONTRATACION ADMINISTRATIVA}

\section{Concurso: exigencia del Proyecto técnico}

CONSIDERANDO: Que centrada la sentencia recurrida en el incontestable argumento de la falta de proyecto técnico previo que exige el párrafo 2 del artículo 38 del Reglamento de Contratación de las Corporaciones Locales de 9 de enero de 1953, no puede darse otra solución al problema litigioso que la confirmación de la misma, pues si este requisito se califica de indispensable en los supuestos del número 5 del artículo 37 del mismo Reglamento, su omisión no tiene o puede tener otra consecuencia que la nulidad del concurso celebrado por el Ayuntamiento de Lugo para la adjudicación de su servicio de limpiezas, así como del procedimiento o actuaciones en que se plasmó.

CoNSIDERANDO: Que esta ineficacia está recogida en los propios preceptos reglamentarios invocados y confirmada en el artículo 47, apartado c), de la Ley de Procedimiento Administrativo, con la figura de la nulidad por haberse prescindido del procedimiento legalmente establecido y de las normas que contienen reglas esenciales para la formación de la voluntad de los Organos colegiados, aplicable al supuesto de autos por lo dispuesto en el número 4 del artículo 1 de dicha Ley Procedimental y sin que sea admisible el argumento de entender, como aduce el Ayuntamiento apelante, que el Pliego de Condiciones sea equivalente al proyecto técnico, pues aquél es consecuencia de éste, según se deduce inequivocamente de la lectura de los artículos 116 y 118 del Reglamento de Servicios de las Corporaciones Locales de 17 de junio de 1955, en relación con los anteriormente citados del Reglamento de Contratación. (Sentencia de 30 de junio de 1980, Ar. 3.367.)

\section{Contrato NULO y OBRA EJECUTADA}

El contrato estaba ya ejecutado por el contratista, quien había hecho entrega de las obras y éstas recibidas provisionalmente por el Ayuntamiento, discutiéndose solamente el importe de las mismas, parte de él reconocido, y los daños y perjuicios; supuesto que, incluso en casos donde la causa de invalidez pudo ser la misma que aquí-sentencias de 22 de enero de 1975 y 21 de abril de 1976-, ha dado solución la doctrina de esta Sala mediante la aplicación no de las cláusulas del contrato ni, por tanto, de las obligaciones de ellas derivadas, sino de los principios generales en cuanto, entre. gada la obra e ingresada la misma en el patrimonio municipal, incluso 
usada ya como en este caso, la simple invalidación abocaria a consecuencias de injusticia, lesivas además para la parte a quien no era imputable la causa de la nulidad; por eso en tales supuestos se ha venido fundando la obligación municipal de abonar el precio de la obra al contratista en el enriquecimiento injusto o el cuasi contrato de gestión de negocios de la Administración y el ejercicio de una "actio in rem verso» determinantes de la obligación del pago en cuanto la obra ejecutada quedó en su poder. (Sentencia de 29 de octubre de 1980, Ar. 3.964.)

\section{REVISIÓN DE PRECIOS EN LA ADMINISTRACIÓN LOCAL}

CONSIDERANDO: Que no puede confirmarse la sentencia apelada que sostiene la vigencia del Decreto de 25 de febrero de 1955, por el cual se suspendió la aplicación del apartado e), número 1 , del repetido artículo 57 del Reglamento de Contratación de las Corporaciones Locales, pues frente a las resoluciones aisladas que esta Sala pudo haber dictado aceptando tal tesis, se alza el criterio jurisprudencial contrario, que debe estimarse consolidado por su mayor abundancia y reiteración en virtud de las razones del parale. lismo que existe entre el régimen juridico de la contratación administrativa local y el que rige en la esfera central, tal y como declara la sentencia de 17 de noviembre de 1978, en la que se sintetiza toda esa anterior jurisprudencia, reiterando la aplicabilidad y vigencia de dicha norma reglamentaria en virtud de la derogación tácita que del citado Decreto de 1955 se produjo con la entrada en vigor de los Decretos-leyes, también citados, de 10 de octubre de 1963 y 4 de febrero de 1964, y que nuevamente se declara en la más reciente sentencia de 27 de octubre de 1979. (Sentencia de 21 de junio de 1980, Ar. 3.328.)

\section{EXPROPIACION FORZOSA}

\section{JURADO: CONSTITUCIÓN}

El apelante en sus alegaciones en esta segunda instancia, pretende la declaración de nulidad por defecto de constitución del Organo tasador creado por la vigente Ley expropiatoria, al no disponer el expropiado en dicho Jurado de un técnico que velara por sus intereses; pero esta petición no puede acogerla la Sala, al no tener competencia ni atribuciones para modificar las leyes, sino que, por el contrario, su actuación está sometida a las mismas, y si la Ley dispone que el vocal técnico, en caso de expropiaciones por Entidades locales, será designado por la Corporación local interesada, así ha de hacerse mientras siga en vigor esa regulación del artículo 85 , número $2^{\circ}$, de la Ley de Expropiación Forzosa. (Sentencia de 17 de octubre de 1980, Ar. 3.576.) 


\section{PRemio de afeCción: BASE de APLICACIÓN}

CoNSIDERANDo: Que en cuanto al premio de afección que el recurrente soiicita que recaiga sobre la totalidad del justiprecio, debe mantenerse el pronunciamiento del Tribunal de Instancia, que lo ha referido justamente el concepto por el valor del suelo, pues ya ha declarado con reiteración esta Sala que al propietario de los bienes sólo le corresponde el premio de afección en relación con el bien de que se le priva y excluyendo cualquier otra indemnización que por otro concepto le sea concedida, razonando esta doctrina con las motivaciones que se recogen en la sentencia de 6 de mayo de 1971, y se reiteran en la de 7 de febrero de 1975, que han sido mantenidas en las sentencias de 16 de abril de 1975, 27 de diciembre de 1978 y 5 de junio de 1979, entre otras que en ellas se citan. (Sentencia de 15 de octubre de 1980, Ar 3.549.)

\section{FUNCIONARIOS}

ADMINISTRACIÓN LOCAL: INTERINOS, EVENTUALES, TEMPOREROS: PAGO DE CUOTAS A LA M.U.N.P.A.L.

Considerando: Que el tema debatido en el recurso se refiere a la impugnación por la Diputación Provincial de Málaga de la Orden del Ministerio del Interior, fecha de 8 de noviembre de 1977, en el particular de su norma 9. , apartado 2; habiendo declarado anteriormente la Sala, sentencias de 9 de febrero y 23 de noviembre de 1979, entre otras, que tanto la Orden como la dicha norma están ajustadas al Ordenamiento Jurídico porque: $1 . ;$, la Orden se dictó en cumplimiento de la autorización conferida por el Decreto 1409 , de 1977 , en su artículo $5 .^{\circ} ; 2 .^{\circ}$, al imponerse a las Corporaciones locales el abono, a la Mutualidad Nacional de Previsión de la Administración Local, de las cuotas atinentes a los funcionarios integrados y antes interinos, eventuales, temporeros o contratados, como el Decreto 2175, de 25 de agosto de 1978, estableció el cómputo recíproco de cotizaciones entre la MUNPAL y los diversos regímenes de la Seguridad Social, con ello quedó resuelta y excluida la posible duplicidad en el pago a que se refiere la Entidad actora; $3^{\circ}$, la sentencia de la Sala de 27 de junio de 1977 decidió cuestión análoga planteada respecto a la norma 8.' de la Orden de 11 de septiembre de 1974, y 4.; ha de mantenerse el mismo criterio antes seguido, en razón al principio de unidad de doctrina del artículo 102-1-b) de la Ley de lo Contencioso-Administrativo. (Sentencia de 15 de octubre de 1980, Ar. 3.571.) 


\section{JURISDICCION CONTENCIOSO-ADMINISTRATIVA}

\section{EJERCICIO DE ACCIONES POR LAS CORPORACIONES lOCALES}

Considerando: Que en la contestación a la demanda se propone la excepción procesal de inadmisibilidad, al amparo del artículo 82-f), en relación con el 57-2-d), ambos de la Ley Jurisdiccional, con base en la alegación de que al escrito de interposición del presente recurso no se acompañó el previo dictamen de Letrado, a que se refiere el artículo 370 de la Ley de Régimen Local y el 338 del Reglamento de Organización de las Corporaciones Locales, como requisito necesario para el ejercicio de acciones por parte de estas Corporaciones; pero tal motivo de inadmisibilidad no puede prosperar, por cuanto, en contra de lo que se argumenta en la contestación, los dos artículos últimamente citados no exigen que el dictamen se acompañe al escrito de interposición, sino que basta con que en la certificación del correspondiente acuerdo conste que éste ha sido adoptado previo tal dictamen-sentencia de la Sala 3." del Tribunal Supremo de 12 de diciembre de 1977, entre otras-, y tal extremo consta en la certificación del acuerdo municipal de interposición del presente recurso, de 15 de septiembre de 1977, en la cual se hace constar que dicho acuerdo fue adoptado "previo dictamen jurídico emitido por el Letradon, que se menciona personalmente, «e informe del señor Secretario" de la Corporación. (Sentencia de 25 de junio de 1980, Ar. 3.345.)

\section{NotifiCACIÓN DEFECTUOSA}

Si en la notificación no se indicó el recurso de reposición, falta ésta que fue subsanada por la Administración a petición del interesado, no cabe alegar inadmisibilidad del recurso contencioso, pues al ser la primera notificación defectuosa, no pudo empezar a correr el plazo para la interposición del recurso de reposición, doctrina ésta recogida en reiteradas sentencias del Tribunal Supremo, entre las cuales pueden citarse la de 4 de febrero de 1970, que califica de viciosa o deficiente la notificación que omite toda referencia al recurso de reposición, la de 24 de enero de 1972, 11 de diciembre de 1973, etc. (Sentencia de 20 de septiembre de 1980, Ar. 3.500.)

\section{POLICIA MUNICIPAL}

1. ACTIVIDADES MOLESTAS, INSALUBRES, NOCIVAS Y PELIGROSAS: MATADERO MUNICIPAL

Previamente es menester poner de relieve que la obra aprobada por el Ayuntamiento sobre ampliación del matadero municipal constituye de for- 
ma indiscutible actividad insalubre, comprendida en consecuencia en el Reglamento aprobado por el Decreto de 30 de noviembre de 1961, como se infiere no ya de su propia natiuraleza, sino del hecho de figurar incluso recogida en el Nomenclátor anejo al mismo, lo que obliga a la Corporación municipal a ajustar su proceder en esta materia a las normas dictadas con carácter general y en aras del interés público que se contienen en las citadas disposiciones para la limitación y control de tales actividades; $y$ si bien es cierto que, como alega el señor Abogado del Estado, el requisito de la previa obtención de licencia para el ejercicio de las mismas sólo afecta a los administrados, únicos sujetos sometidos a la acción de intervención de la Administración actuañte, también lo es, sin embargo, que ello no puede suponer en absoluto que dicha Administración quede relevada del cumplimiento de los requisitos que los demás sujetos deben cumplir para obtener la licencia, lo que supone que, a falta de procedimiento más específico, las normas de trámite previstas para el otorgamiento de licencias a particulares o a otra Administración pública deben ser observadas igualmente cuando de realización de obras por el propio Ayuntamiento se trata, no solamente para garantizar la efectividad de las competencias concurrentes en la materia, sino también para hacer posible que, en aras de un inexcusable principio de igualdad ante la ley, la legalidad de las obras municipales, desde el punto de vista del cumplimiento de los requisitos afectantes a la actividad incómoda, sea examinada por los organismos competentes, y especialmente por el propio Ayuntamiento, con idéntico rigor y en presencia de idénticos antecedentes técnicos y jurídicos que cuando se trata de fiscalizar la actividad de los administrados, lo que exige una idéntica sustanciación del procedimiento, aun cuando el mismo no se resuelva en el otorgamiento de una licencia, sino en el acuerdo de aprobación de un proyecto. (Sentencia de 27 de octubre de 1980, Ar. 3.958.)

\section{CANTERAS: LICENCIA MUNICIPAL AL EFECTO}

Considerando: Que, en primer término, debe rechazarse la petición de nulidad de los actos impugnados que, con base en el artículo 116 de la Ley de Minas de 21 de julio de 1973, pretende el actor, sosteniendo que el Alcalde carece de facultades para ordenar el cese de la explotación de una cantera por cuanto dicho precepto se las asigna privativamente al Ministro de Industria; porque el criterio sentado por esta Sala al fijar el alcance de los artículos 65 de la Ley de 19 de julio de 1944 y 183 del Reglamento de 9 de agosto de 1946 es aplicable al mencionado artículo 116, puesto que es sustancial reproducción del 65 precitado y las intrascendentes variaciones de su texto no justifican una doctrina distinta si se tiene en cuenta la naturaleza de la explotación $y$, en consecuencia, ha de entenderse que tales disposiciones no obstan a la competencia que al Ayuntamiento confieren los artículos 101 de la Ley de Régimen Local, 21 del Reglamento de Servicios de las Corporaciones de este orden y 47 y 165 de la Ley del Suelo de 12 de mayo de 1956 en cuanto al movimiento de tierras, al que son asimilables los trabajos propios de una cantera por cuanto consisten en el allanamiento $o$ en la excavación-sentencias de 29 de marzo y 13 de noviembre de 1963 y 13 de diciembre de 1969-. (Sentencia de 11 de julio de 1980, Ar. 3.427.) 


\section{LICENCIAS: CARÁCTER REGLADO}

Conforme a una reiteradisima doctrina de este Tribunal, recogida, como más reciente, en la sentencia de 11 de febrero de este año 1980, la concesión o denegación de una licencia municipal no es un acto arbitrario de la Cor. poración que discrecionalmente puede actuar como estime oportuno, sino que es un acto reglado, tanto en su contenido como en su otorgamiento, que requiere el examen de las circunstancias de hecho concurrentes en cada caso concreto y la posterior determinación de su adecuación o no a las Ordenanzas municipales vigentes, exigiéndose en caso de denegación, que la correspondiente resolución se hará de forma motivada y fundada, señalándose los hechos o circunstancias concurrentes en el objeto de la licencia cuestionada que sean contrarios a la Ordenanza aplicable. (Sentencia de 26 de septiembre de 1980, Ar. 3.452.)

\section{Resolución de la Comisión Provincial de Urbanismo que EXIGE QUE EL AYUNTAMIENTO DECLARE ERRONEA UNA LICENCIA OTORGADA}

Considerando: Que el proceso va dirigido contra un acuerdo municipal en virtud del cual el Ayuntamiento, estimando haber otorgado legalmente una licencia de obras, deniega su anulación a pesar de que la Comisión Provincial de Urbanismo la ha declarado erróneamente concedida con expresión de que el Ayuntamiento concedente debe hacer aplicación de lo dispuesto en el artículo 172 de la Ley del Suelo de 12 de mayo de 1956, partiendo de la hipótesis de que los artículos 5.4 y 172 de la Ley del Suelo citada y 16, en relación con el 9, del Reglamento de Servicios de las Corporaciones Locales de 17 de junio de 1955, concedan a dicha Comisión competencia para anular por errónea una licencia de obras concedida por el Ayuntamiento, no puede, sin embargo, incluirse dentro de esa competencia la facultad de sustituir la potestad de anulación directa por la de imponer al Ayuntamien. to la obligación de que proceda por si mismo a acordar dicha anulación, pues las facultades que en defensa de la legalidad urbanistica se confieren por vía subrogatoria a las citadas Comisiones o a otros organismos no de. ben desnaturalizarse hasta el punto de olvidar que subrogar no es más que poner a una persona o cosa en el lugar de otra, lo cual trasladado al campo del Derecho y referido al aspecto subjetivo de la relación jurídica, significa tanto como autorizar a un sujeto el ejercicio de las acciones o facultades que vienen atribuidas a su titular que no las ejercita o lo hace indebidamente, $y$ esto es esencialmente distinto que obligar a dicho titular a que las ejercite en contra de su propio criterio y voluntad, imponiéndole una conducta que a su juicio es contraria a Derecho $y$ en tal sentido deben interpretarse los citados preceptos. (Sentencia de 30 de octubre de 1980, Ar. 3.998.) 


\section{LICENCIA DE APERTURA DE ESTABLECIMIENTO: MEDIDAS CORRECTORAS POSTERIORES}

Considerando: Que entrando ya en la cuestión de fondo del recurso, la actora argumenta que la instalación del garaje para aparcamiento de coches, que constituye la finalidad del «Garaje Estraunza», fue objeto tanto de licencia municipal, como de autorización por la Delegación de Industria de Vizcaya, teniendo abierta su ventilación interior sin que durante siete años nadie presentase denuncia alguna; alegaciones éstas que para nada inciden sobre el objeto de esta litis, pues es indudable que abierta una industria con todos los requisitos legales, esto nunca impedirá el que los Alcaldes del Municipio en que esté enclavada puedan adoptar medidas para corregir los malos olores, ruidos y expulsión de gases tóxicos, ya por aplicación de la normativa general consignada en los artículos 101-h), 116-c) y e) y 117-b) de la Ley de Régimen Local, como en los artículos 1-1.., 3-1, 4, 5-c) y 6 del Reglamento de Servicios de las Corporaciones Locales, que exige una intervención de policía en la actividad de los administrados mediante órdenes individuales de defensa y protección de personas, como por la aplicación más específica de lo previsto en el artículo 36 del Reglamento de Actividades Molestas, Insalubres, Nocivas y Peligrosas, de 30 de noviembre de 1961, que permite el requerimiento de los Alcaldes para corrección de deficiencias que sean comprobadas. (Sentencia de 15 de junio de 1980, Ar. 3.435.)

\section{LICENCIA DE OBRAS: CONCEPTO}

Considerando: Que según el Reglamento de Servicios de las Corporaciones Locales, los Ayuntamientos podrán intervenir la actividad de sus administrados mediante el otorgamiento de previa licencia en los casos de apertura de establecimientos industriales; intervención que tenderá a verificar si las instalaciones reúnen las condiciones de tranquilidad, seguridad y salubridad, y las que, en su caso, estuvieren dispuestas en los planes de urbanización debidamente aprobados (arts. 1, 8 y 22); dicha licencia municipal es término equivalente al de autorización administrativa, siendo conceptuada por la doctrina y por la jurisprudencia del Tribunal Supremo -sentencias de 22 de febrero y 8 de mayo de 1965,7 y 19 de junio de 1972 y 20 de agosto de 1976 (sic)-como una declaración de voluntad de la Administración pública con la que se permite a otro sujeto público o privado el ejercicio de un derecho, del que ya era titular, previa valoración de la legalidad de tal ejercicio. (Sentencia de 7 de julio de 1980, Ar. 3.416.)

\section{LICENCIA DE OBRAS: CONDICIONES IMPUESTAS SIN BASE LEGAL}

CONSIDERANDO: Que los Ayuntamientos, como integrantes de la Administración pública, ostentan evidentemente la potestad de someter el ejercicio de determinados derechos individuales, como es el de propiedad, a la exi- 
gencia de la previa licencia, con la finalidad de armonizar el disfrute del derecho, con las exigencias que impone el interés general, y a la cual se refieren tanto el artículo 165 de la Ley del Suelo, como el artículo $8 .^{\circ}$ del Reglamento de Servicios de las Corporaciones Locales.

Considerando: Que de todas formas y aun reconociendo que el derecho de propiedad debe ser conceptuado como limitado por su propia esencia, y ejercitable, por tanto, sólo dentro del marco establecido por las leyes y demás disposiciones que conjuntamente forman el bloque de la legalidad, lo que resulta patente es que cualquier condicionamiento del dominio, y en consecuencia del «ius aedificandi», tiene que estar recogido en disposiciones legales o reglamentarias de carácter general, previamente establecidas por los órganos competentes y mediante el procedimiento previsto en cada caso, de tal manera que el condicionamiento o la limitación afecte no a un supuesto singular dependiente de la discrecionalidad administrativa, sino a la generalidad de supuestos análogos, para que sea la propia Administración la primera obligada a exigir y a cumplir el condicionamiento por ella establecido. (Sentencia de 7 de octubre de 1980, Ar. 3.875.)

\section{LICENCIAS: PAGO DE TASA: NO SUPONE NECESARIAMENTE EL OTORGAMIENTO DE LA LICENCIA}

CoNSIDERANDo: Que tampoco cabe estimar la alegación relativa a los pretendidos efectos de concesión que para el recurrente tendria la percepción de la tasa municipal, porque la percepción de la tasa, acto tributario para el cual el otorgamiento de licencia constituye mero presupuesto de hecho $y$, por tanto, con un alcance diferente en Derecho, ni prueba ni presupone, en general, este otro acto, salvo que asi aparezca de modo explicito $y$ suficientemente expresivo en el expediente. (Sentencia de 10 de julio de 1980, Ar. 2.434.)

\section{LICENCIA DE OBRAS: PRINCIPIOS DE IGUALDAD ANTE LA LEY Y DE LEGALIDAD}

CONSIDERANDO: Que, en cuanto a la pretendida infracción del principio de igualdad ante la ley, que sienta el artículo 3 del Fuero de los Españoles y el artículo 2 del Reglamento de Servicios de 17 de junio de 1955, es lo cierto que en ellos se establece la llamada igualdad de los administra. dos con carácter programático y constitucional en aquél y mencionado por numerosa jurisprudencia; mas este principio no implica que se sigan otorgando licencias que vulneren la legalidad vigente en el Ayuntamiento demandado, por el hecno de que se hubieran otorgado otras, puesto que aun como preeminencia debe observarse el de legalidad, sin que ésta no pueda omitir $u$ olvidar, en aras del de igualdad, puesto que sin legalidad no puede existir igualdad, puesto que para que el principio invocado tenga operatividad, se necesita que la legalidad vigente tenga posibilidad de permitir lo 
edificado, pues del hecho de que varias veces se hubiera conculcado la legalidad, no puede racionalmente inferirse de que tenga que seguir haciéndose en respeto del principio de igualdad. (Sentencia de 20 de octubre de 1980, Aranzadi 3.919.)

\section{LICENCIA DE OBRAS: SUSPENSIÓN}

ConsIDERANDO: Que también es acertada la doctrina del Tribunal a quo cuando matiza que el derecho a indemnización de los gastos del proyecto que el artículo 22, número 3, de la Ley del Suelo de 1956 establece, ha de entenderse supeditado a la viabilidad y procedencia legal de concesión de la licencia solicitada. Solamente en este caso tiene justificación tal indemnización, pues cuando por otros motivos extraños al Acuerdo de suspensión, debiera ser denegada la licencia faltaría el presupuesto origen de aquel derecho, dicho en expresión más jurídica, la causa que le motiva, que para tal, habria de concurrir como única, pero existiendo otros impedimentos legales, como en este caso sucede, que imposibilitan la edificación en la forma proyectada, no es ya solamente el acuerdo suspensivo, sino también la falta de acomodación del proyecto a las normas urbanisticas lo que determinaría, incluso por si sola, la resolución denegatoria. (Sentencia de 25 de octubre de 1980, Ar. 3.949.)

\section{RUINA}

\section{Declaración}

La declaración de ruina ha de descansar en unas situaciones facticas, las que por su especial naturaleza han de ser extraídas fundamentalmente de los informes técnicos y que éstos conviene sean valorados con arreglo a las normas de prioridad que otorgan la coincidencia de opiniones de la mayoria, la superior titularidad facultativa y la mayor objetividad, indepen. dencia e imparcialidad que ofrecen los peritos ajenos a los intereses de las partes afectadas por la declaración que recaiga, circunstancias las dos últimas que precisa y plenamente se dan en el susodicho Arquitecto municipal; prevalencia del susodicho dictamen pericial que si predicable en general, ha de producir y produce la plena convicción de la Sala en el caso concreto que se enjuicia. (Sentencia de 23 de junio de 1980, Ar. 3.338.)

\section{EDIFICIO FUERA DE ALINEACIÓN}

Considerando: Que en la sentencia de 2 de marzo de 1970 se declara que la jurisprudencia de este Alto Tribunal ha estimado concurrente la causa $c$ ) del número 2 del artículo 170 de la Ley del Suelo-de 1956-cuando el edificio se encuentre afectado por un Plan-sentencia de 4 de diciembre de 1965-, 
y ello, por cierto, aunque el coste de la reparación sea inferior al 50 por 100 del valor actual del edificio-sentencia de 7 de junio de 1963-, cuando se halle fuera de alineación-sentencia de 7 de marzo de 1961-o bien cuando la finca carezca de las exigencias imprescindibles de habitabilidad-sentencia de 12 de noviembre de 1963-. (Sentencia de 17 de julio de 1980, Aranzadi 3.437.)

\section{Procedencia de SU declaración}

De toda esta prolija enunciación de daños y obras a realizar aparece como una constante unánimemente apreciada por los técnicos informantes la necesidad de obras que rebasan el limite de la normalidad técnica de los medios ordinarios de reparación, entre cuyas obras se hallan las que consisten en reconstruir-sentencias de 22 de septiembre de 1959; 7 de marzo, 6 y 14 de octubre de 1963; 28 de enero de 1964, 29 de mayo de 1968, etc.-, pues no son procedimientos normales los que suponen o requieren la previa demolición de partes del inmueble para ser sustituidas por otras-sentencias de 23 de junio de 1969, 28 de enero de 1964, 9 de noviembre de 1970 y 12 de abril de 1973, entre otras-. (Sentencia de 3 de julio de 1980, Ar. 3.400.)

\section{Obras ordenadas por el AyUntamiento: no es PREcisa LA LICENCIA}

CONSIDERANDO: Que la licencia de obras y la orden de su ejecución son actos administrativos que teniendo un distinto origen, facultativo en aquélla $y$ obligatorio en ésta, constituyen, sin embargo, manifestaciones de una misma potestad de intervención y control de la actividad de los administrados que participan de igual naturaleza juridica y tienen idéntico efecto legitimador de esa actividad que autorizan en el primer caso e imponen en el segundo, y asi lo proclama de manera suficientemente explícita la Ley del Suelo de 1956, y hoy su Texto Refundido de 1976, cuando incluyen a ambas figuras en el mismo capítulo bajo la rúbrica de aintervención en la edificación y uso del suelo", en el que se contiene una regulación que, aun separada en secciones distintas, trasciende esa esencial identidad de efecto autorizante que tienen dichas figuras jurídicas y que se manifiesta muy claramente en los términos con que el artículo 171 de la Ley-184 del Texto Refundido-atribuye igual consecuencia a la falta de licencia $u$ orden de ejecución, asi como al incumplimiento de sus respectivas condiciones $y$ que no consienten otra doctrina que la ya sustentada en la sentencia de 24 de noviembre de 1969, según la cual y por aceptación de los considerandos de la apelada, la orden de ejecución de determinadas obras supone la concesión de licencia para realizarlas, quedando ésta limitada a una función meramente fiscal y de com. probación de que las obras efectuadas corresponden con lo que se ha mandado al administrado. (Sentencia de 10 de julio de 1980, Ar. 3.426.) 


\section{PROCEDIMIENTO ADMINISTRATIVO}

\section{Cómputo de Plazo}

Considerando: Que, en contra de la tesis en la que se funda la sentencia apelada, hay que entender que la exclusión del día en el que se comunicó el acto no impide que el plazo se cumpla en igual fecha del mes correspondiente; porque únicamente asi comprendería con exactitud un mes natural, del que excedería en un día si venciera al agotarse el del mismo número del siguiente a la notificación; de esta manera, en el caso litigioso, practicada la intimación del acuerdo el 3 de junio, el día inicial del término sería el 4 inmediato, y el final, el 3 de julio, con lo que cabalmente lo integrarian los días de un mes natural completo. (Sentencia de 23 de julio de 1980, Ar. 3.440.)

\section{RESPONSABILIDAD DE LA ADMINISTRACION}

\section{RESPONSABILIDAD PATRIMONIAL OBJETIVA}

ConsIDERANDO: Que el principio general de la responsabilidad patrimonial objetiva de la Administración pública es una de las más importantes conquistas del Estado de Derecho, que actualmente aparece incorporado a todos los Ordenamientos positivos más progresivos, entre los cuales se incluye, en este aspecto, el español, donde se inicia la consagración legal de dicho principio en la Ley de Régimen Local, se realiza con amplitud en los artículos 121 de la Ley de Expropiación Forzosa de 16 de diciembre de 1954 y 40 de la Ley de Régimen Jurídico de la Administración del Estado de 26 de julio de 1957, y se eleva a principio de la máxima jerarquía en el artículo 106, 2, de la Constitución, por lo cual no es dable ya dudar de que constituye pieza fundamental de nuestro Estado de Derecho, cuyo natural carácter expansivo impide en su aplicación toda interpretación que obstaculice su plena realización material y obliga, en congruente coordinación con el principio de interpretación más favorable a los administrados, dar preferencia al criterio hermenéutico que conduzca al examen de la acción, $y$ en tal sentido debe entenderse que el plazo de un año, que establece el artículo 122 de la Ley de Expropiación citada, aplicable a la Administración local, según dispone el 133,2 , de su Reglamento, es un plazo de prescripción que se interrumpe por su ejercicio ante los Tribunales, de acuerdo con lo previsto en el articulo 1.973 del Código Civil, y esta doctrina encuentra refuerzo, si fuere necesario, en el propio texto del citado artículo 122, que emplea la palabra "prescribe", asi como en la naturaleza de la acción que contempla, pues al ser ésta una acción de indemnización de daños y perjuicios no existe razón alguna para excluirla del instituto de la prescripción, al cual tradicionalmente viene sometida tal clase de acciones, como asi ha entendido la jurisprudencia en 
sentencias, entre otras, de 11 de noviembre de 1965, 4 de noviembre de 1969 , 11 de diciembre de 1974 y 2 de abril de 1979, cuya doctrina debe aquí reiterarse. (Sentencia de 4 de julio de 1980, Ar. 3.410).

\section{SOLARES E INMUEBLES DE EDIFICACION FORZOSA}

\section{DESAH UCIO: INDEMNIZACIÓN}

CONSIDERANDO: Que sin perjuicio de anteriores vacilaciones doctrinales $e$ incluso jurisprudenciales respecto de la naturaleza de la extinción o conversión de los derechos arrendaticios constituidos sobre la finca incluida en el Registro de Solares, la aplicación del desahucio administrativo y su carácter previo, la naturaleza y alcance de la indemnización, vía competente para acordarla, puede hoy sentarse de modo terminante que, a partir de la sentencia de 5 de abril de 1974 se ha producido una corriente unificadora que, ya en las de 11 de junio de 1975 y 25 de mayo de 1976, ha venido a sentar que el artículo 149 citado prescribe la extinción de los arrendamientos y demás derechos personales sobre la finca incluida en el Registro fundada en razones de interés público (aunque paralelas al interés privado del propietario) y como consecuencia de una actuación administrativa (ulterior a la decisión de inclusión) que en rigor viene a operar la privación singular de aquellos derechos, lo que en el concepto del artículo 1 de la Ley de 16 de diciembre de 1954 significa una expropiación que, con arreglo a sus principios, no pue. de tener lugar sin que a la desposesión del bien o derecho preceda la indemnización-sentencia de 17 de marzo de 1978-; principios que tienen su traducción positiva en el artículo 41 del Reglamento del Registro de Solares, que para la posesión consecuencia del artículo 149 citado remite al desahucio administrativo, conforme al 54 del Reglamento de Expropiación Forzosa, según los plazos y condiciones del 53, es decir, cumplido el requisito previo al que se refiere como inexcusable el 52-2-sentencias citadas de 17 de marzo de 1978, 25 de mayo de 1976, 11 de junio de 1975-; doctrina que, por otra parte, se afirma unánimemente después a través de las de 13 y 29 de diciembre de 1976, 30 de abril de 1977, y de modo ya reiterado y sin variaciones en las últimas de 17 de marzo de 1978, 19 de abril y 3 de octubre de 1979. (Sentencia de 25 de junio de 1980, Ar. 3.342.)

\section{URBANISMO}

\section{FiJACión DE zONAS Y DESTINo URBANfSTICo}

Es propio del Plan General, a tenor del artículo 9-1-a), la división en zonas y el establecer su destino urbanístico, extremo no modificable por el Parcial, como aquí se pretende-doctrina asimismo ya sentada en sentencia como la que se invoca de 28 de octubre de 1977-. (Sentencia de 28 de octubre de 1980, Aranzadi 3.960.) 


\section{Ordenanzas municipales contrarias al Plan}

Dada la naturaleza de los Planes de Urbanización, como normas o dispasiciones generales de ordenación urbana, éstos deben prevalecer sobre las Ordenanzas que no pueden modificarlos, aunque para su aprobación se hubieran seguido los trámites previstos en el artículo 33 de la Ley del Suelo, en relación con el 32, en razón del distinto rango jerárquico de una y otra norma, y de que, según el artículo 23 de la Ley del Régimen Juridico del Estado, las disposiciones administrativas no podrán vulnerar los preceptos de otra de rango superior. (Sentencia de 14 de octubre de 1980, Ar. 3.929.)

\section{Plan general y planes parciales}

Es incuestionable la aseveración de la demandante, según la cual los planes parciales están subordinados a los generales, cuyo contenido desarro llan-artículo 10 de la Ley del Suelo de 12 de mayo de 1956-, hasta el punto de que la Sala considera a éstos fuente jurídica de superior rango en la materia. (Sentencia de 27 de octubre de 1980, Ar 3.954.)

\section{Plan Parcial: falta}

«Es constante la doctrina jurisprudencial existente sobre operancia directa del Plan General, sin necesidad del Parcial, cuando en aquél, como aquí ocurre, el terreno se divide en zonas señalando el destino de cada una de ellas, y se establecen otras previsiones capaces de contar de antemano con las líneas maestras y principales directrices de la ordenación urbanística del sector»-sentencias de 26 de diciembre de 1964, 16 de diciembre de 1970, 30 de junio de 1973 y 5 de octubre y 21 de diciembre de 1974-. (Sentencia de 20 de octubre de 1980, Ar. 3.997.)

\section{Planes: Importancia DEL eSTUdio eCONOMico}

ConsIDERANDO: Que con mejor fundamentación se han invocado en el recurso ahora examinado las notorias deficiencias existentes en el Documento numero 3 del Plan-Estudio económico-, cuya trascendencia es sumamente grave, como viene exponiendo de manifiesto la doctrina jurisprudencial -sentencias del Tribunal Supremo de 7 de junio de 1973, 14 y 24 de octubre de 1977-, que ha subrayado la importancia de lo prevenido en el artículo 10, número 2, a), de la Ley del Suelo de 1956, y su relación con lo exigido, para los Planes generales, en el artículo 9, número 2, e), siendo particularmente clarificadora en este extremo la citada sentencia de 24 de octubre de 1977, expresiva de que si bien es cierto que el estudio economico-financiero "ses un elemento común al plan general y al parcial y que ha de existir, en ambos casos, el documento acreditativo de tal exigencia, no puede dejar de resal- 
tarse la diferencia esencial que también existe, puesto que en el supuesto plan general bastará acreditar, desde una perspectiva amplia general, las posibilidades económico-financieras del territorio y la población, mientras que en el caso del plan parcial o especial resulta necesario detallar los medios económico-financieros disponibles, además de su adscripción a la ejecución del plan». (Sentencia de 25 de octubre de 1980, Ar. 3.947.)

\section{Terreno destinado a ví pública}

CoNSIDERANDo: Que el que la Administración haya dejado pasar tantos años sin acometer la realización de las correspondientes obras, puede ser debido a carencia de recursos, a negligencia de los encargados de activar el planeamiento urbanístico de la ciudad o a cualquier otra posible circunstancia; mas nada de ello puede servir para desvirtuar el imperio de la ordenación urbana del sector, en cuanto ello constituye una de las principales caracteristicas de este Ordenamiento-artículos 45, 47 y 61 de la Ley del Suelo de 1956-, teniendo en cuenta que abstracción de posibles responsabilidades, si es que realmente se ha dado el supuesto de negligencia, o de funcionamiento anormal de la Administración, lo cierto y real en este caso es la imposibilidad de acceder a la pretensión de los accionantes de este proceso, esto es, a que se le conceda licencia para construir en terrenos en parte afectados por la apertura de una nueva calle, ya que ello es imposible, porque sería sobreponer el interés particular sobre el público, lo cual seria motivo de nulidad de pleno derecho del acto administrativo que lo infringiera, a tenor de lo dispuesto en el artículo 47-1-b) de la Ley de Procedimiento Administrativo. (Sentencia de 5 de julio de 1980, Ar. 3.415.)

\section{ZONAS VERDES: PROTECCIÓN ESPECIAL QUE ESTABLECE LA LEY DE 12 DE DICIEMBRE DE 1963}

CONSIDERANDO: Que precisamente para proteger las zonas libres y espacios libres previstos u obligados, el precepto citado prohíbe que, una vez aprobados los Planes se introduzca en ellos sin cumplir los requisitos que la citada Ley prevé, «ninguna clase de modificación que tuviere por objeto una diferente zonificación o uso urbanístico de las zonas verdes o espacios libres previstos en el plan», prohibición terminante de cualquier modificación de la zonificación o el uso resultante, con independencia de su alcance cuantitativo, porque es la modificación misma lo prohibido y de ahi que no deba permitirse, aunque sea mínima, aunque suponga permuta de superficie o incluso ampliación en otro lindero, aunque sea un mero cambio de zona verde en vial de uso público, tal como puede entenderse que resulta, en general, de sentencias de esta Sala, como las de 12 de enero de 1973, 12 de febrero de 1975 o 5 de junio de 1978, supuestos ésos que, por tanto, también deben acordarse con los requisitos y por el órgano especial citados; lo cual significa un desplazamiento a éste de la decisión discrecional en cuanto a la conveniencia de la remodelación de esas zonas y su alcance $y$, por tanto, 
en esa decisión, por mínima que sea, no cabe sustitución por otro brgano administrativo ni tampoco por el Tribunal al revisar los actos emanados, porque precisamente el decidir acerca del alcance (no de la pura legalidad) de la modificación en su aspecto cuantitativo, o sea, sobre su incidencia global en superficie del parque, se está pronunciando sobre aspectos de oportunidad o conveniencia que son discrecionales. (Sentencia de 9 de julio de 1980. Aranzadi 3.421.)

\section{ZONA MARITIMO-TERRESTRE}

\section{EXIGENCIA DE LA LICENCIA MUNICIPAL}

Si al tenor del artículo 10 de la Ley de Costas de 26 de abril de 1969 corresponde al Ministerio de Obras Públicas la gestión y tutela de la zona marítimo-terrestre, también es verdad que estas atribuciones no excluyen la intervención municipal, como explícitamente deja a salvo el mismo precepto y se desprende del artículo 15 al disponer que el otorgamiento de la concesión no exime a su titular de la obtención de las licencias, permisos y autorizaciones legalmente procedentes, entre ellas, sin duda, las exigidas en las Leyes del Suelo y del Régimen Local y en las normas concordantes, puesto que, según se indica en la sentencia de esta Sala de 30 de junio de 1979, invocando el artículo $10^{\circ}$ de la última de las leyes mencionadas, todo el territorio nacional forma parte del de los Municipios por cuanto éstos integran el Estado español. (Sentencia de 28 de junio de 1980, Ar. 3.366.)

Nemesio RodRf́GUEz MoRo 
REVL-1981, núm. 211. RESEÑA DE SENTENCIAS 